\title{
A Halogen-Bond Donor Catalyst for Templated Macrocyclization
}

\author{
Kévin Guillier, Elsa Caytan, Vincent Dorcet, Florence Mongin, Élise Dumont, and Floris Chevallier*
}

\begin{abstract}
A halogen-bond templated 1:1 macrocyclization in solution is reported. Tetra(iodoperfluorophenyl) ethers were used as halogenbonded exotemplates in a substoichiometric amount (5 mol\%). Pyridine-containing macrocyclic architectures were formed by ruthenium-catalyzed tandem metathesis/transfer hydrogenation sequence using sodium borohydride and methanol as nondihydrogen hydrogen source. The halogen-bonded stabilization energies were analyzed relying on density functional theory.
\end{abstract}

The interest in molecular self-assembly, ${ }^{[1]}$ molecular recognition ${ }^{[2]}$ and interlocking structures ${ }^{[3]}$ has increased steadily over the last decades, making supramolecular chemistry one of the fastest growing areas in nanotechnology. Supramolecular catalysis was among the first applications in this field and has notably allowed a better understanding of the enzymatic reaction mechanisms through the development of simplified model systems. ${ }^{[4]}$ In order to increase efficiently the rate or the selectivity of chemical reactions, several synthetic supramolecular catalytic systems have been developed. These latter involve recognition and organization through reversible covalent (metal-ligand) and noncovalent (van der Waals forces, $\pi$-interactions, hydrophobic effect, electrostatic interactions, hydrogen bonding) connections between the binding sites. ${ }^{[5]}$ Among the noncovalent forces, $D-H \cdots A$ hydrogen bonds ${ }^{[6]}$ ( $D$ and $A$ are the bond donor and acceptor, respectively) were more frequently used as assembly motifs in the supramolecular organocatalytic processes than their D-X $\cdots$ A halogen counterparts. ${ }^{[7,8]}$

In this context, we recently described the construction of pyridine-containing macrocyclic architectures by olefin metathesis / hydrogenation reactions. ${ }^{[9]}$ The use of a stoichiometric amount of 4,6-dichlororesorcinol (4,6-diCl-res) as an exotemplate allowed us to self-organize two aza-heterocyclic units by $\mathrm{O}-\mathrm{H} \cdots \mathrm{N}$ hydrogen bonds (Figure 1a). In the current study, we report on the utilization of a substoichiometric amount of halophenyl ethers for the $\mathrm{C}-\mathrm{I} \cdots \mathrm{N}$ halogen-bond templated 1:1 macrocyclization. For this purpose, we focused on sequential metathesis/hydrogenation processe $^{[10]}$ to achieve the macrocyclic ring closure under mild

[*] Prof. E. Dumont, Dr. F. Chevallier

Univ Lyon, Ens de Lyon, CNRS UMR 5182,

Université Claude Bernard Lyon 1, Laboratoire de Chimie,

F69342, Lyon, France

E-mail: floris.chevallier@ens-lyon.fr

K. Guillier, Dr. E. Caytan, Dr. V. Dorcet, Prof. F. Mongin,

Dr. F. Chevallier

Univ Rennes, CNRS, ISCR (Institut des Sciences Chimiques de

Rennes) - UMR 6226

F35000, Rennes, France

Supporting information and the ORCID identification number(s) for the author(s) of this article can be found under:

https://doi.org/10.1002/anie.XXXXXXX. a.

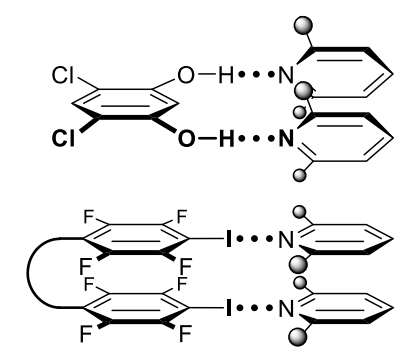

Figure 1. Proposed pre-organization for hydrogen-bond (a), and halogen-bond (b) templated construction of pyridine-containing macrocycles.

conditions, while avoiding diastereomeric mixture of cis/trans olefin products and thus facilitate the analysis (Figure 1b).

We started our investigations employing bisallylfunctionalized pyridine derivative $\mathbf{1 a}$ as model substrate in the presence of $10 \mathrm{~mol} \%$ of second generation Grubbs catalyst (3a). Then, sodium borohydride and methanol were used as nondihydrogen hydrogen source for transfer hydrogenation, ${ }^{[11]}$ at ambient temperature and pressure (Table 1). ${ }^{[10 \mathrm{j}]}$ The absence of any organization additive led to cyclized product $\mathbf{2 a}$ which could be isolated in only $6 \%$ yield (Table 1 , entry 1 ), linear oligomers were formed as major products by an acyclic diene metathesis (ADMET) / hydrogenation pathway. As we have already demonstrated with dihydrogen as hydrogen source, ${ }^{\left[{ }^{[]}\right.}$a ditopic hydrogen-bond donor such as 4,6-dichlororesorcinol used in a stoichiometric amount (with reference to the hydrogen-bonding motifs) appeared to be able to assemble efficiently two pyridine units (Table 1, entry 2 ). Repeating the reaction with 0.1 equivalent of 4,6-dichlororesorcinol resulted in the formation of $\mathbf{2 a}$ in $21 \%$ yield together with ADMET condensation polymerization compounds (Table 1, entry 3 ).

Due to the polarizability of iodine and to the electronegativity of fluorine, iodoperfluorocarbon derivatives have shown their ability to form strong halogen bonds. ${ }^{[7]}$ Among these compounds, substituted iodotetrafluorobenzenes proved to be particularly effective to orient substrates in crystal engineering by intramolecular $\pi-\pi$ stacking interaction and intermolecular halogen bonding in supramolecular assemblies with pyridine derivatives. ${ }^{[12]}$ When employing a stoichiometric amount of the Metrangolo and Resnati's templating tecton $\mathbf{4 a}^{[12 a, 13]}$ (Figure 2), the hydrogenated macrocyclic architecture $\mathbf{2 a}$ was obtained in $76 \%$ yield (Table 1 , entry 4 ). This result suggests that $4 a$ can act as an exotemplate to orient two pyridine molecules by halogen bonding in the solution. In contrast to 4,6-dichlororesorcinol, a decrease from 0.5 to 0.1 equivalent in the amount of pentaerythritol derivative $\mathbf{4 a}$ did not involve a yield loss (Table 1, entry 5). Moreover, by reducing the tetratopic halogen-bond donor 
Table 1. Evaluation of reaction parameters for two-component macrocyclization. ${ }^{[a]}$<smiles>C=CCN(Cc1cccc(CN(CC=C)C(=O)OCc2ccccc2)n1)C(=O)O</smiles><smiles></smiles>

$1 \mathrm{a}$

$2 a$<smiles>CN1CCN(C)C1[P+](Cl)(Cl)(Cl)/C=C\c1ccccc1</smiles>
$\mathrm{PCy}_{3}$
$\mathrm{Cl}$
$\mathrm{Cl}=\mathrm{Pu}=$
$\mathrm{PCy}$
$\mathrm{PCh}$

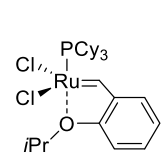

3b

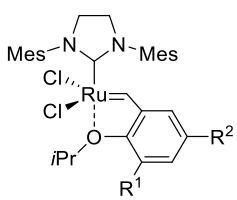

3d, $R^{1}=R^{2}=H$ 3e, $R^{1}=P h, R^{2}=H$ 3f, $\mathrm{R}^{1}=\mathrm{H}, \mathrm{R}^{2}=\mathrm{NO}_{2}$

\begin{tabular}{|c|c|c|c|c|}
\hline Entry & {$[R u]$} & Additive & $x$ & yield $[\%]^{[b]}$ \\
\hline 1 & $3 a$ & - & - & 6 \\
\hline 2 & $3 a$ & 4,6-diCl-res ${ }^{[c]}$ & 0.5 & 70 \\
\hline 3 & $3 a$ & 4,6-diCl-res ${ }^{[c]}$ & 0.1 & 21 \\
\hline 4 & $3 a$ & $4 a$ & 0.5 & 76 \\
\hline 5 & $3 a$ & $4 a$ & 0.1 & 83 \\
\hline 6 & $3 a$ & $4 a$ & 0.05 & 81 \\
\hline 7 & $3 b$ & $4 a$ & 0.05 & 37 \\
\hline 8 & $3 c$ & $4 a$ & 0.05 & 55 \\
\hline 9 & $3 d$ & $4 a$ & 0.05 & 88 \\
\hline 10 & $3 e$ & $4 a$ & 0.05 & 85 \\
\hline 11 & $3 f$ & $4 a$ & 0.05 & 85 \\
\hline 12 & $3 a$ & $4 b$ & 0.05 & 17 \\
\hline 13 & $3 a$ & $4 c$ & 0.05 & 10 \\
\hline 14 & $3 a$ & $4 d$ & 0.05 & 7 \\
\hline 15 & $3 a$ & $4 e$ & 0.05 & 7 \\
\hline 16 & $3 a$ & $4 f$ & 0.05 & 26 \\
\hline 17 & $3 a$ & $4 \mathrm{~g}$ & 0.05 & 39 \\
\hline 18 & $3 a$ & $4 \mathrm{~h}$ & 0.05 & 32 \\
\hline 19 & $3 a$ & $4 i$ & 0.05 & 24 \\
\hline
\end{tabular}

[a] Reaction conditions: [1a $]_{t=0}=10^{-2} \mathrm{M}$ in 1,2-dichloroethane, [Ru] (10 mol \%), additive (x equiv), $50{ }^{\circ} \mathrm{C}, 2 \mathrm{~h}$, then $\mathrm{CH}_{3} \mathrm{OH}$ (30 equiv), $\mathrm{NaBH}_{4}$ (4 equiv), $25^{\circ} \mathrm{C}, 24 \mathrm{~h}$. [b] Isolated yield. [c] 4,6-Dichlororesorcinol.

4a loading to 0.05 equivalent, the reaction remained efficient to give a comparable $81 \%$ isolated yield of 2 a (Table 1 , entry 6 ). Other commercially available ruthenium alkylidene complexes were investigated in this study. While metathesis precatalysts 3a,d-f showed similar results (Table 1, entries 6,9-11), lower yields were observed in the presence of non-imidazolylidene carbene complexes $\mathbf{3 b - c}$ (Table 1, entries 7-8). The efficiency displayed by first- and second-generation ruthenium-based metathesis catalysts clearly showed that bulky and electron-donor $\mathrm{N}$-heterocyclic carbene ligands are necessary to promote the bimolecular macrocyclization reaction. It has to be noted that the highest yield of $88 \%$ was reached with orthoisopropoxybenzylidene-coordinated catalyst $\mathbf{3 d}$ (Table 1, entry 9).
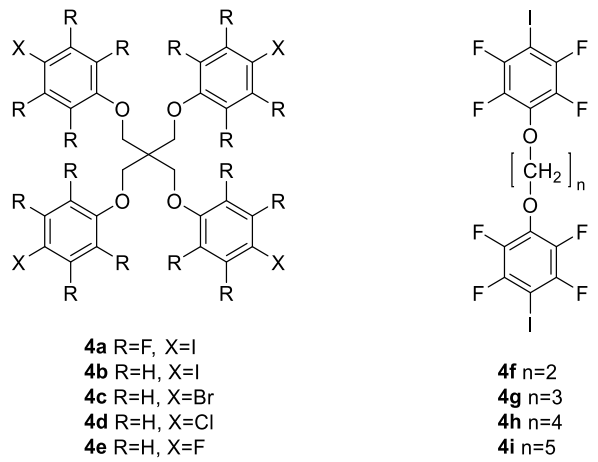

Figure 2. Halophenyl ethers $4 a-i$.

Next, different halobenzene-based halogen-bond donors (Figure 2) were tested in the double olefin metathesis/hydrogenation reaction (Table 1, entries 12-19). Among the tetratopic pentaerythritol derivatives studied, 4a showed the highest template efficiency (Table 1, entry 6), whereas the other halogenated tetraphenyl ethers $\mathbf{4 b}$-e appeared to be unable to pre-organize properly two pyridine units in the reaction conditions (Table 1, entries 12-15). These results can be correlated with the strengths of the halogen-bonding interactions. The halogen bond is the result of a positive electrostatic potential located on the surface of the halogen atom, usually referred to as a $\sigma$-hole. That region of lower electron density becomes larger with increasing size of the halogen $(\mathrm{F}<\mathrm{Cl}<\mathrm{Br}<\mathrm{I})$, although fluorine is rarely involved in halogen bonding because of its low polarizability. ${ }^{[14]}$

Furthermore, substitution of hydrogen atoms with fluorine atoms on the template aromatic ring directly affects the selectivity of the reaction. Ditopic- (4f-i), and especially tetratopic- (4a) perfluorinated iodoarenes gave higher yields than parahalophenol derivatives $\mathbf{4 b - e}$ (Table 1 , entries $6,12-19$ ). These results can be explained by the effects of the aromatic fluorine substitution on the strengths of the halogen-bond interactions. Indeed, the electron-withdrawing effect of additional fluorine atoms increases dramatically the positive potential of the halogen $\sigma$-holes. ${ }^{[15]}$

Utilizing the optimized reaction conditions (Table 1, entry 9), we then examined the templated macrocyclization by tandem olefin metathesis/transfer hydrogenation with various olefins (Table 2). In the presence of $5 \mathrm{~mol} \%$ of halophenyl ether $\mathbf{4 a}$ and $10 \mathrm{~mol} \%$ of second generation Hoveyda-Grubbs catalyst 3d, the cyclized and reduced products $\mathbf{2 a - d}$ were obtained in 86 to $93 \%$ 
yield, which is comparable with those reported for the hydrogen bond templated synthesis with similar systems. ${ }^{[9]}$ Pyridine- and bipyridine-containing macrocyclic architectures $\mathbf{2 a - b}$ were isolated in similar conditions from the corresponding bisallylfunctionalized derivatives 1a-b. Moreover, tris(heterocycles) 1cd based on the alternation of electron-poor (pyridyl) and electronrich (thienyl or 3,4-ethylenedioxythienyl) heterocycles, which showed interesting chain-length dependent fluorescence properties $^{[16]}$ and specific coiled conformations due to intramolecular nitrogen-sulfur inter-ring interactions ${ }^{[17]}$ led to the expected products $\mathbf{2 c}-\mathbf{d}$ in high yields.

Table 2. Halogen-Bond-Catalyzed Macrocyclization by Sequential Double Olefin Metathesis/Transfer Hydrogenation with Different Aza-Heterocyclic Units. ${ }^{[a]}$

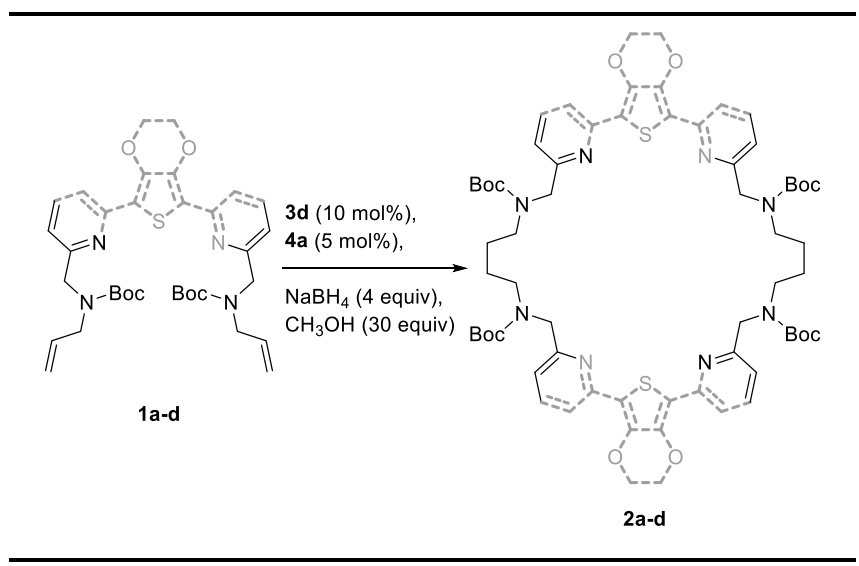

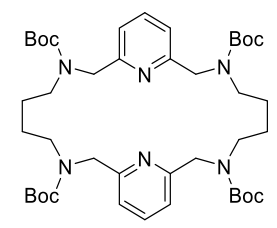

$2 \mathrm{a}(88 \%)^{[\mathrm{b}]}$

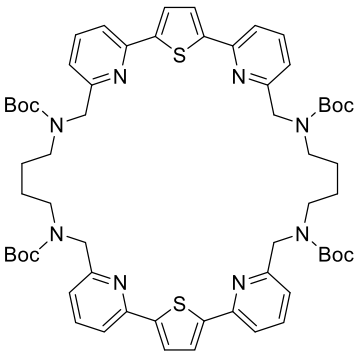

2c $(93 \%)^{[\mathrm{b}]}$

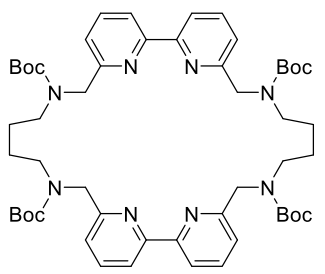

2b $(93 \%)^{[\mathbf{b}]}$

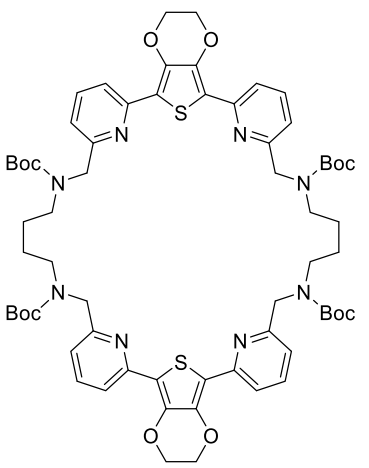

$2 \mathbf{d}(86 \%)^{[\mathrm{b}]}$ [a] Reaction conditions: i) $0.100 \mathrm{mmol}$ of $\mathbf{1 a}-\mathbf{d}, 0.005 \mathrm{mmol}$ of $\mathbf{4 a}$, and 0.010 $\mathrm{mmol}$ of $\mathbf{3 d}$, in $10 \mathrm{~mL}$ of 1,2 dichloroethane were heated in a Schlenk flask at $50{ }^{\circ} \mathrm{C}$ for $2 \mathrm{~h}$. ii) $3.00 \mathrm{mmol}$ of $\mathrm{CH}_{3} \mathrm{OH}, 0.40 \mathrm{mmol}$ of $\mathrm{NaBH}_{4}$ were added at $25^{\circ} \mathrm{C}$, and the reaction was stirred for $24 \mathrm{~h}$. [b] Isolated yield.
In addition, the interactions between the tetratopic halophenyl ethers 4a-e and two aza-heterocyclic units 1a have been investigated by NMR spectroscopy and quantum chemistry calculations. ${ }^{[18]}$ While ${ }^{1} \mathrm{H}$ - and ${ }^{19} \mathrm{~F}-\mathrm{NMR}$ experiments (twodimensional and selective one-dimensional HOESY) highlighted a fast exchange on the NMR timescale, the optimized geometry obtained by density functional theory calculations strongly suggests a 1:2 complex including two halogen-bonding arrangements. In the case of a $\mathbf{1 a / 4 a}$ mixture in a 2:1 ratio, the I...N interatomic distances were determined to be 2.94 and 2.99 $\AA$ with $\mathrm{C}-\mathrm{I} \cdots \mathrm{N}$ angles of 176.5 and $173.5^{\circ}$ (Figure 3). The conformation of the halogen-bond donor molecule involves intramolecular $\pi \cdots \pi$ stacking interactions between pairs of parallel fluorophenyl rings. The conformational flexibility restriction associated with an increase in the proximity of the two reactive alkene ends therefore allow high cyclization efficiencies, although the $\mathbf{1 a} / \mathbf{4 e}$ complex is weakly bounded with disruption of one $\mathrm{X} \cdots \mathrm{N}$ interaction. Finally, the stabilization energy between free and self-associated states were determined (Table 3). These results confirm that the template abilities displayed in Table 1 are directly related to the halogen-bond interaction energies.

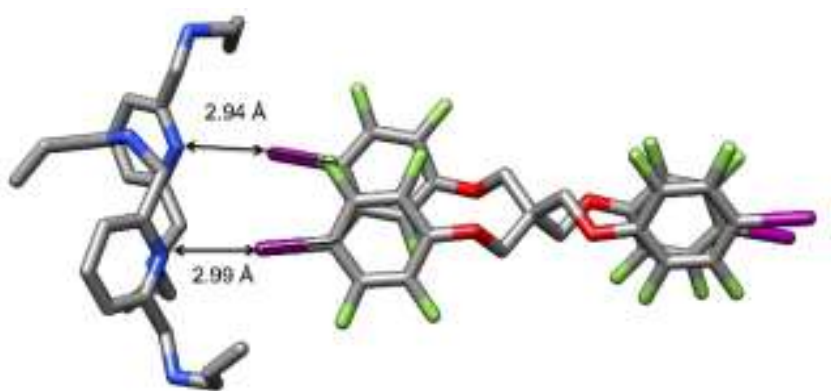

Figure 3. Optimized DFT/PCM structure at the M06-2X/6-311+G(d,p) level of the non-covalent interactions between the halogen-bond donor $\mathbf{4 a}$ and two equivalents of the halogen-bond acceptor $1 \mathrm{a}$ in 1,2-dichloroethane $(\mathrm{H}$ atoms and Boc protecting groups are omitted for clarity).

Table 3. Structural and energetic characterization of the interactions at the M06-2X/6-31+G(d,p)-PCM level of theory. ${ }^{[a]}$

\begin{tabular}{llll}
\hline Entry & XB donor & $\mathrm{X} \cdots \mathrm{N}$ distances $[\AA]$ & $\Delta \mathrm{E}^{\text {stab }}\left[\mathrm{kcal} . \mathrm{mol}^{-1}\right]$ \\
\hline 1 & 4a & $2.94,2.99$ & -17.1 \\
2 & 4b & $3.15,3.16$ & -11.5 \\
3 & 4c & $3.05,3.07$ & -9.6 \\
4 & 4d & $3.17,3.19$ & -7.5 \\
5 & 4e & $2.99,3.76$ & -6.8 \\
\hline
\end{tabular}

[a] Structures and energies of association were determined for the complexes formed by the halogen-bond donors $4 a-e$ and two equivalents of the halogen-bond acceptor $\mathbf{1 a}$. 
In conclusion, we have demonstrated that a tetratopic iodoperfluorophenyl halogen-bond donor can be efficiently used in substoichiometric quantities as an exotemplate in solution. The nonmetallic template efficiency in the two-component macrocyclization of pyridine-containing derivatives appears to be directly correlated to the binding strength of the halogen-bond donor and the reversible intermolecular associations between the interacting partners were highlighted by computational investigations. We believe that the present study will open new perspectives in the development of tunable and efficient supramolecular organocatalysts based on halogen bonding in solution.

\section{Acknowledgements}

We are grateful to the Universite de Rennes 1, the École Normale Supérieure de Lyon, and the CNRS for support. The authors thank the SYSPROD project and AXELERA Pôle de Compétitivité for financial support (PSMN Data Center). We thank Prof. Jérôme Lacour for helpful discussions and valuable comments.

\section{Conflict of interest}

The authors declare no conflict of interest.

Keywords: halogen bonds • template synthesis • organocatalysis $\cdot$ metathesis $\cdot$ hydrogen transfer

[1] a) J.-M. Lehn, Supramolecular Chemistry: Concepts and Perspectives, $\mathrm{VCH}$, Weinheim, 1995; b) Molecular Self-Assembly: Advances in Chemistry, Biology and Nanotechnology (Ed.: J. P. Comrie), Nova Science Publishers, New York, 2011; c) Molecular Self-Assembly: Advances and Applications (Ed.: A. D. Q. Li), Pan Stanford, Singapore, 2013.

[2] a) K. Ariga, H. Ito, J. P. Hill, H. Tsukube, Chem. Soc. Rev. 2012, 41, 5800-5835; b) Supramolecular Chemistry: From Molecules to Nanomaterials, Vol. 3: Molecular Recognition (Eds.: P. A. Gale, J. W. Steed), Wiley \& Sons, Chichester, 2012; c) E. Persch, O. Dumele, F. Diederich, Angew. Chem. Int. Ed. 2015, 54, 3290-3327.

[3] a) Molecular Catenanes, Rotaxanes and Knots: A Journey Through the World of Molecular Topology (Eds: J.-P. Sauvage, C. DietrichBuchecker), Wiley-VCH, Weinheim, 1999; b) F. Aricó, J. D. Badjic, S. J. Cantrill, A. H. Flood, K. C. F. Leung, Y. Liu, J. F. Stoddart, Top. Curr. Chem. 2005, 249, 203-259; c) R. S. Forgan, J.-P. Sauvage, J. F. Stoddart, Chem. Rev. 2011, 111, 5434-5464.

[4] M. Raynal, P. Ballester, A. Vidal-Ferran, P. W. N. M. van Leeuwen, Chem. Soc. Rev. 2014, 43, 1734-1787.

[5] a) Supramolecular Catalysis (Ed.: P. W. N. M. van Leeuwen), Wiley-VCH, Weinheim, 2008; b) P. Ballester, A. Vidal-Ferran, P. W. N. M. van Leeuwen in Advances in Catalysis (Eds.: B. C. Gates, H. Knözinger), Elsevier, 2011, pp. 63-126, c) P. Ballester, P. W. N. M. van Leeuwen, A. Vidal, in Comprehensive Inorganic Chemistry II (Eds.: J. Reedijk, K. Poeppelmeier), Elsevier, 2013, pp. 457-486; d) M. Raynal, P. Ballester,
A. Vidal-Ferran, P. W. N. M. van Leeuwen, Chem. Soc. Rev. 2014, 43 , 1660-1733; e) C. J. Brown, F. D. Toste, R. G. Bergman, K. N. Raymond, Chem. Rev. 2015, 115, 3012-3035; f) S. H. A. M. Leenders, R. GramageDoria, B. de Bruin, J. N. H. Reek, Chem. Soc. Rev. 2015, 44, 433-448.

[6] V. Martí-Centelles, M. D. Pandey, M. I. Burguete, S. V. Luis, Chem. Soc. Rev. 2015, 115, 8736-8834.

[7] a) P. Metrangolo, F. Meyer, T. Pilati, G. Resnati, G. Terraneo, Angew. Chem., Int. Ed. 2008, 47, 6114-6127; b) T. M. Beale, M. G. Chudzinski, M. G. Sarwar, M. S. Taylor, Chem. Soc. Rev. 2013, 42, 1667-1680; c) S. Schindler, S. M. Huber, Top. Curr. Chem. 2015, 359, 167-203; d) L. C. Gilday, S. W. Robinson, T. A. Barendt, M. J. Langton, B. R. Mullaney, P. D. Beer, Chem. Rev. 2015, 115, 7118-7195; e) D. Bulfield, S. M. Huber, Chem.-Eur. J. 2016, 22, 14434-14450; f) G. Cavallo, P. Metrangolo, R. Milani, T. Pilati, A. Priimagi, G. Resnati, G. Terraneo, Chem. Rev. 2016, 116, 2478-2601; g) R. Tepper, U. S. Schubert, Angew. Chem., Int. Ed. 2018, 57, 6004-6016.

[8] a) For examples of halogen bond catalyzed methodologies, see: $\mathrm{C} . \mathrm{Xu}$, C. C. J. Loh, J. Am. Chem. Soc., 2019, 141, 5381-5391, and references therein; b) For a significant example of halogen ion templated interlocked molecules formation, see: C. J. Serpell, N. L. Kilah, P. J. Costa, V. Félix, P. D. Beer, Angew. Chem., Int. Ed. 2010, 49, 5322-5326.

[9] A. S. Trita, T. Roisnel, F. Mongin, F. Chevallier, Org. Lett. 2013, 15, 3798 3801.

[10] a) J. Louie, C. W. Bielawski, R. H. Grubbs, J. Am. Chem. Soc. 2001, 123, $11312-11313$; b) S. D. Drouin, F. Zamanian, D. E. Fogg, Organometallics 2001, 20, 5495-5497; c) P. Børsting, P. Nielsen, Chem. Commun. 2002 2140-2141; d) A. Fürstner, A. Leitner, Angew. Chem., Int. Ed. 2003, 42 , 308-311; e) B. Schmidt, M. Pohler, Org. Biomol. Chem. 2003, 1, 25122517; f) C. Menozzi, P. I. Dalko, J. Cossy, Synlett 2005, 2449-2452; g X. Miao, C. Fischmeister, C. Bruneau, P. H. Dixneuf, J.-L. Dubois, J.-L. Couturier, ChemSusChem 2012, 5, 1410-4; h) G. K. Zieliński, C. Samojłowicz, T. Wdowik, K. Grela, Org. Biomol. Chem. 2015, 13, 2684 2688; i) G. K. Zieliński, K. Grela, Chem.-Eur. J. 2016, 22, 9440-9454; j) T. Connolly, Z. Wang, M. A. Walker, I. M. McDonald, K. M. Peese, Org Lett. 2014, 16, 4444-4447.

[11] D. Wang, D. Astruc, Chem. Rev. 2015, 115, 6621-6686.

[12] a) T. Caronna, R. Liantonio, T. A. Logothetis, P. Metrangolo, T. Pilati, G. Resnati, J. Am. Chem. Soc. 2004, 126, 4500-4501; b) J. Xu, X. Liu, J. K.-P. Ng, T. Lin, C. He, J. Mater. Chem. 2006, 16, 3540-3545; c) P. Metrangolo, F. Meyer, T. Pilati, D. M. Proserpio, G. Resnati, Chem.-Eur. J. 2007, 13, 5765-5772; d) D. W. Bruce, P. Metrangolo, F. Meyer, T. Pilati, C. Praesang, G. Resnati, G. Terraneo, S. G. Wainwright, A. C. Whitwood, Chem.-Eur. J. 2010, 16, 9511-9524; e) M. A. Sinnwell, L. R. MacGillivray, Angew. Chem., Int. Ed. 2016, 55, 3477-3480.

[13] E. Guido, P. Metrangolo, W. Panzeri, T. Pilati, G. Resnati, M. Ursini, T. A. Logothetis, J. Fluorine Chem. 2005, 126, 197-207.

[14] a) P. Politzer, P. Lane, M. C. Concha, Y. Ma, J. S. Murray, J. Mol. Model. 2007, 13, 305-311; b) P. Politzer, J. S. Murray, M. C. Concha, J. Mol. Model. 2007, 13, 643-650; c) P. Politzer, J. S. Murray, T. Clark, Phys. Chem. Chem. Phys. 2010, 12, 7748-7757.

[15] K. E. Riley, J. S. Murray, J. Fanfrlík, J. Řezáč, R. J. Solá, M. C. Concha, F. M. Ramos, P. Politzer, J. Mol. Model. 2011, 17, 3309-3318.

[16] a) F. Chevallier, M. Charlot, C. Katan, F. Mongin, M. Blanchard-Desce, Chem. Commun. 2009, 692-694; b) F. Chevallier, M. Charlot, F. Mongin, B. Champagne, E. Franz, K. Clays, M. Blanchard-Desce, ChemPhysChem 2016, 17, 4090-4101.

[17] D. Tilly, F. Chevallier, F. Mongin, Synthesis 2016, 48, 184-199.

[18] For details, see the Supporting Information. 
Table of Contents

\section{COMMUNICATION}

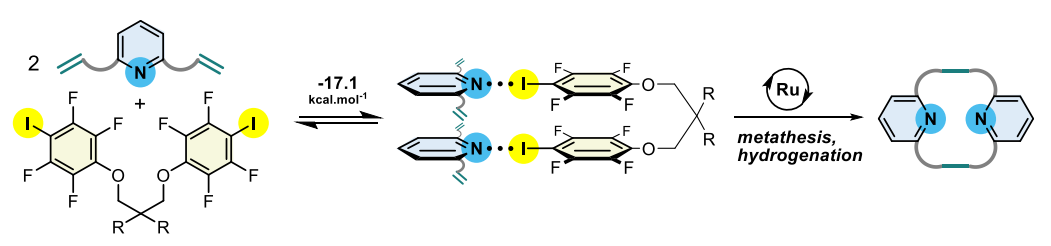

lodoperfluorophenyl ethers were used as exotemplates in a substoichiometric amount to perform a halogen-bond templated 1:1 macrocyclization through a tandem olefin metathesis/transfer hydrogenation.
Kévin Guillier, Elsa Caytan, Vincent Dorcet, Florence Mongin, Élise Dumont, and Floris Chevallier*

\section{Page No. - Page No.}

A Halogen-Bond Donor Catalyst for Templated Macrocyclization 